\title{
Evaluation of Simple In-house Method for Direct Microbial Identification of Positive Blood Culture by MALDI-TOF Technology
}

\author{
Amira Hamed Mohamed Afifi* and Rehab Mohamed Mohamed Ateya \\ Department of Clinical Pathology, Faculty of Human Medicine, Zagazig University, Egypt \\ *Corresponding author
}

\section{A B S T R A C T}

Keywords

MALDI-TOF mass spectrometry, Blood culture, Direct microbial identification

Article Info

Accepted: 10 January 2021 Available Online: 10 February 2021
Blood stream infections are leading causes of mortality and morbidity throughout the world. The rapid identification of pathogens causing sepsis enable early initiation of appropriate antimicrobial therapy. Matrix assisted laser desorption ionization time-of-flight (MALDI-TOF) mass spectrometry has been established as a rapid reliable method for identification of cultured bacterial and fungal isolates. However, conventional processing requires overnight incubation of the blood culture broth on solid media prior to MALDITOF MS analysis, delaying organism identification, Methods: 530 positive blood culture bottles were analyzed MALDI-TOF MS by direct In-house methods and results were compared to results obtained by conventional culture on sold media Results: among 530 positive blood cultures, the in-house method correctly identified $74 \%$ of cultures to the species level and $16 \%$ to genus level and $10 \%$ gave no identification. Correct identification rate among Gram negative organisms was $96 \%$ (196/204) and $88.8 \%$ (286/322) among Gram positive organisms. Conclusion: This study demonstrated the effectiveness of Inhouse method for identifying bacteria directly from positive blood culture bottles. We propose our in-house method as an efficient and successful method to reduce time of identification of causative agent of bacteremia/sepsis.

\section{Introduction}

Blood stream infections are one of the most important causes of mortality and morbidity all over the world (Bearman and Wenzel, 2005).The rapid identification of causative pathogen of sepsis enable early initiation of appropriate antimicrobial therapy. This can improve patient outcome, reduce length of hospital stay (Delport et al., 2016), reduce hospital costs and reduce development of microbial resistant pathogens (Doern and Butler-Wu, 2016). In the last years, Matrix assisted laser desorption ionization time-offlight (MALDI-TOF) mass spectrometry has been established as a rapid reliable method for identification of cultured isolates of bacteria and fungi. MALDI- TOF have already become a part of routine diagnostic work-up in many institutions. However, conventional processing requires culturing of the positive blood culture broth on solid media with overnight incubation prior to MALDI-TOF MS analysis, this delays organism identification by 18-24 hours (Fenselau and Demirev, 2001). Several commercial kits 
have been developed for identification of microorganisms directly from positive blood cultures. However, because of the high reagent cost, complexity of procedures, relatively time consumption and moderate rates of bacterial identification, particularly for Gram-positive bacteria, these kits could not be integrated as a part of routine diagnostic work-up (Zhou et al., 2017).

Various in-house protein extraction protocols have been described for direct identification of microorganisms from positive blood culture bottles, aiming to prepare microbial protein extract, purified from blood cells, proteins and culture media to minimize interference with direct identification of organisms by MALDI-TOF (Chen et al., 2013) (Chien et al., 2016)(Faron et al., 2017) (Martiny et al., 2012).

In the current study we evaluated the performance and accuracy of a simple rapid cost effective in-house method for direct microbial identification of positive blood culture broths by comparing obtained results with the results of conventional method following culture on solid media using the Vitek MS (bioMérieux) system.

\section{Materials and Methods}

This study was conducted at the Clinical Microbiology laboratory of Zagazig University Hospital from January 2020 to June 2020. The study included all positive blood culture broths that arrived at the Microbiology laboratory as a part of routine work up for patients admitted to the hospital. All aerobic bottles (BacT/Alert FA plus), anaerobic bottles (BacT/Alert FN plus) and pediatric aerobic (BacT/Alert PF plus) bottles were incubated in the BACT/ALERT 3D $\AA$ instrument (bioMérieux) up to 5 days, or until they flagged as positive. All bottle types are charcoal free. Each positive blood culture bottle was processed by both routine method and the direct in-house identification protocol for performance comparison. The majority of the bottles were processed on the same day that they flagged positive.

\section{Identification by Routine method}

Gam stain was performed directly from aliquots of positive blood cultures. Then according to morphology of organisms, blood culture media were subcultured on solid media (blood, Mac Conkey, chocolate agar) then incubated for $18-24$ hours at $37{ }^{\circ} \mathrm{C}$ in a $5 \%$ CO2 atmosphere. When every easts detected by Gram stain, the sample was additionally subcultured on Sabouraud media, which was incubated at $37{ }^{\circ} \mathrm{C}$ for 48 hours. For positive anaerobic blood culture, additional blood agar plates were incubated in anaerobic jar. Following incubation, isolated bacterial colonies were spotted onto a MALDI-TOF MS disposable target plate (Vitek MS, bioMérieux) and $1 \mu$ l of matrix, alpha-cyano-4-hydroxycinnamic acid matrix $(\alpha C H C A)$ was deposited to each spot and air dried for MALDI- TOF MS analysis. For fungal isolates, $0.5 \mu \mathrm{l}$ formic acid was deposited, air dried and overlaid with matrix. The target plate was then read and analyzed by the Vitek MS IVD system. Quality control was performed using the reference $E$. coli ATCC 8739 strain the reference strain was spotted in the central well of the disposable slide and overlaid with1 $\mu$ of matrix, alpha-cyano-4-hydroxycinnamic acid matrix ( $\alpha \mathrm{CHCA})$. The organisms were then directly applied to disposable VMS target plates.

\section{In-house direct identification protocol}

For each positive culture, $1.5 \mathrm{ml}$ of positive blood culture fluid was transferred to reaction tube and centrifuged at 13,000 rpm for 1 minute to separate red blood cells from the 
bacterial cells. $50 \mu \mathrm{l}$ of Triton $(100 \times)$ at concentration of $0.1 \%$ (Sigma For Chemicals, Egypt) was added to the supernatant and mixed gently then centrifuged at $13,000 \mathrm{rpm}$ for 1 minute. The supernatants were discarded and the pellets were re-suspended in $1.5 \mathrm{ml}$ distilled water and centrifuged for $1 \mathrm{~min}$ at $13,000 \mathrm{rpm} .50 \mu \mathrm{l}$ of acetonitrile and $50 \mu \mathrm{l}$ of formic acid (70\%) were added to the pellet and mixed. After centrifugation for 1 minute at 13,000 rpm, $1 \mu \mathrm{l}$ of supernatant was spotted in duplicate onto wells of VITEK-MS target slide and air-dried at room temperature. Each spot was overlaid with $1 \mu \mathrm{l}$ of an alpha-cyano4-hydroxycinnamic acid matrix. The spots were air dried and the target slide was then loaded and analyzed by the Vitek MS bioMérieux.

\section{MALDI-TOF mass spectrometry analysis}

The target plate was analyzed by the Vitek® MS V3.2 bio-Mérieux system. MALDI-TOF instruments use an ionizing laser beam to ionize and vaporize the abundant structural elements (primarily ribosomal proteins) of bacteria and yeasts and analyze the weight and relative abundance of each particle to generate a spectrum. The sequence and size of ribosomal proteins are highly conserved among different bacterial species. So, the generated Spectra of unknown organisms are compared to the reference spectra in the VITEK MS database, and identification is obtained by matching the most similar spectrum in the database to the unknown organism. The best identification match is expressed as confidence percentage (from 0 to $99.9 \%$ ). Identification to the species level was considered when confidence value 95-99.9\% while identification to the genus level was considered when confidencevalue90-94\%. If the confidence value was $\geq 50-94 \%$, and there was a choice of 2-4 organisms all within the same genus the result was recorded as 'genus level but if the choice between organisms of different genera, the results was recorded as non-identified.

\section{Statistical analysis}

The identification results of in -house method were compared with the results of conventional method. The correct identification rates was calculated as the number of isolates that were correctly identified by in-house method (up to genus level) divided by number of isolates identified by conventional method. The data was analyzed using the SPSS version 25 to calculate Sensitivity, specificity, positive predictive values (PPV) and negative predictive values (NPV) of In-house method by considering conventional culture on solid media as the gold standard method. Agreement between the In-house method and routine method was done using kappa test. $\mathrm{P}$ value less than $<0.05$ was considered to be significant and $<0.001$ was considered highly significant

\section{Results and Discussion}

A total of 530positive blood culture broths were collected over the study period. 412 of 530 were from aerobic and 14 from anaerobic bottles and 104 from pediatric bottles. The blood cult ure bottles were predominantly (98.7\%) monomicrobial, only7blood culture bottles $(1.3 \%)$ were polymicrobial cultures.60 $\%$ (3 22/537) of isolates were grampositive, $38 \%(204 / 537)$ Gram negative, only $2 \%$ $(11 / 537)$ were yeasts. Table 1 presents microorganism identification results of positive blood culture bottles analyzed by MALDI-TOF using routine method and in house direct method. The most commonly isolated Gram positive cocci were Staph haemolyticus and Staph hominis. While the most commonly isolated Gram negative bacilli were Klebsiella pneumoniae and Escherichia coli. 
Direct in-house method correctly identified $89.8 \%$ of organisms (482/537). The correct identification rates was higher in Gram negative organisms $96 \%(196 / 204)$ versus Gram positive organisms $88.8 \%$ (286/322). None of the yeast isolates were identified by direct in-house methods. Identification to the species level by direct in -house method was $71 \%$ for Gram positive organisms and $83 \%$ for Gram negative organisms (Table 2). Agreement analysis showed significant agreement between in -house method and routine method with kappa of 0.86 and 0.97 for Gram positive and Gram negative organisms, respectively ( $p$ value $<0.001$ ).
In-house rapid identification protocol showed higher sensitivity for Gram negative bacteria than Gram positive bacteria $(88.8 \%$ and $96.1 \%$ respectively). Specificity was $100 \%$ for both groups. The sensitivity and specificity were $100 \%$ for Staph aureus and Escherichia coli to the species level (Table 3).

In our study only $1.3 \%$ (7/530) blood cultures were identified by the Vitek MS system by routine methods to be polymicrobial (composed of 2 bacterial species). Using our In house protocol, single organism was identified in $4 / 7(57 \%)$ blood culture bottles (Table 4).

Table.1 List of organisms identified by routine method, Vitek® MS Blood culture kit and direct in house method

\begin{tabular}{|c|c|c|c|c|}
\hline \multirow[b]{2}{*}{ Organism } & \multirow{2}{*}{$\begin{array}{l}\text { Total } \\
\text { number }\end{array}$} & \multicolumn{3}{|c|}{ Direct In-house method } \\
\hline & & $\begin{array}{c}\text { at the species } \\
\text { level }\end{array}$ & At the genus level & Not identified \\
\hline Staph aureus & 33 & 31 & 2 & 0 \\
\hline Staph epidermidis & 75 & 57 & 13 & 5 \\
\hline Staph haemolyticus & 124 & 93 & 19 & 12 \\
\hline Staph hominis & 83 & 46 & 24 & 13 \\
\hline Micrococcus luteus & 5 & 0 & 1 & 4 \\
\hline Kocuria varians & 2 & 0 & 0 & 2 \\
\hline Total Gram positive & 322 & 227 & 59 & 36 \\
\hline Escherichia coli & 58 & 54 & 4 & 0 \\
\hline Klebsiella pneumoniae & 83 & 72 & 10 & 1 \\
\hline $\begin{array}{l}\text { Pseudomonas } \\
\text { aeruginosa }\end{array}$ & 12 & 7 & 3 & 2 \\
\hline Pseudomonas stuzeri & 6 & 1 & 2 & 3 \\
\hline $\begin{array}{l}\text { Acinetobacter } \\
\text { baumanii }\end{array}$ & 32 & 25 & 7 & 0 \\
\hline Morganella morganii & 4 & 3 & 1 & 0 \\
\hline Burkhorderia cepacia & 3 & 2 & 0 & 1 \\
\hline Enterobacter fecalis & 6 & 5 & 0 & 1 \\
\hline Total Gram negative & 204 & 169 & 27 & 8 \\
\hline Fungus & 11 & 0 & 0 & 11 \\
\hline
\end{tabular}


Table.2 Results of direct In-house method microorganisms' identification in positive blood culture divided to microorganisms' groups

\begin{tabular}{|c|c|c|c|c|c|}
\hline \multirow[t]{2}{*}{ Microorganism groups } & \multirow{2}{*}{$\begin{array}{l}\text { Identification } \\
\text { by routine } \\
\text { culture } \\
\text { dependent } \\
\text { method }\end{array}$} & \multicolumn{3}{|c|}{ In-house rapid identification protocol. } & \multirow[b]{2}{*}{$\begin{array}{c}\text { Correct } \\
\text { identification } \\
\text { rate } \mathrm{n}(\%)\end{array}$} \\
\hline & & $\begin{array}{l}\text { at the species } \\
\text { level } n(\%)\end{array}$ & $\begin{array}{l}\text { Genus level } \\
\text { only n }(\%)\end{array}$ & $\begin{array}{c}\text { Not } \\
\text { identified } \\
\mathrm{n}(\%)\end{array}$ & \\
\hline Gram positive bacteria & 322 & $227(71))$ & $59(18)$ & $36(11)$ & $286(88.8)$ \\
\hline Gram negative bacteria & 204 & $169(83)$ & $27(13)$ & $8(4)$ & 196(96) \\
\hline Fungi & 11 & $0(0)$ & $0(0)$ & $11(100)$ & $0(0)$ \\
\hline Total & 537 & $396(74)$ & $86(16)$ & $55(10)$ & $482(89.8)$ \\
\hline
\end{tabular}

Table.3 Sensitivity, specificity, positive predictive values (PPV) and negative predictive values (NPV) of In-house rapid identification protocol

\begin{tabular}{|c|c|c|c|c|c|c|c|c|c|}
\hline & \multirow[b]{2}{*}{$\begin{array}{c}\text { Total } \\
\text { number }\end{array}$} & \multicolumn{2}{|c|}{ In-house method } & \multirow[b]{2}{*}{$\begin{array}{c}\text { Sensitivity } \\
(\%)\end{array}$} & \multirow[b]{2}{*}{$\begin{array}{l}\text { Specificity } \\
(\%)\end{array}$} & \multirow[b]{2}{*}{$\begin{array}{l}\text { PPV } \\
(\%)\end{array}$} & \multirow[b]{2}{*}{$\begin{array}{l}\text { NPV } \\
(\%)\end{array}$} & \multirow[b]{2}{*}{ Kappa } & \multirow[b]{2}{*}{$P$ value } \\
\hline & & identified & $\begin{array}{c}\text { not } \\
\text { identified }\end{array}$ & & & & & & \\
\hline Staph aureus & 33 & 33 & 0 & 100 & 100 & 100 & 100 & 1 & $<0.001$ \\
\hline Staph epidermidis & 75 & 70 & 5 & 93.3 & 100 & 100 & 98.9 & 0.96 & $<0.001$ \\
\hline Staph haemolyticus & 124 & 112 & 12 & 90.3 & 100 & 100 & 97.2 & 0.94 & $<0.001$ \\
\hline Staph hominis & 83 & 70 & 13 & 84.3 & 100 & 100 & 97.2 & 0.9 & $<0.001$ \\
\hline Micrococcus luteus & 5 & 1 & 4 & 20 & 100 & 100 & 99.3 & 0.33 & $<0.42$ \\
\hline Kocuria varians & 2 & 0 & 2 & 0 & 100 & 100 & 99.6 & 0.1 & $\begin{array}{l}0.81 \\
\mathrm{NS}\end{array}$ \\
\hline Total Gram positive & 322 & 286 & 36 & 88.8 & 100 & 100 & 85.7 & 0.86 & $<0.001$ \\
\hline Escherichia coli & 58 & 58 & $\mathbf{0}$ & 100 & 100 & 100 & 100 & 1 & $<0.001$ \\
\hline $\begin{array}{l}\text { Klebsiella } \\
\text { pneumoniae }\end{array}$ & 83 & 82 & 1 & 98.8 & 100 & 100 & 99.8 & 0.99 & $<0.001$ \\
\hline $\begin{array}{l}\text { Pseudomonas } \\
\text { aeruginosa }\end{array}$ & 12 & 10 & 2 & 83.3 & 100 & 100 & 99.6 & 0.91 & $<0.001$ \\
\hline Pseudomonas stuzeri & 6 & 3 & 3 & 50 & 100 & 100 & 99.4 & 0.66 & 0.04 \\
\hline $\begin{array}{l}\text { Acinetobacter } \\
\text { baumanii }\end{array}$ & 32 & 32 & 0 & 100 & 100 & 100 & 100 & 1 & $<0.001$ \\
\hline $\begin{array}{l}\text { Morganella } \\
\text { morganii }\end{array}$ & 4 & 4 & 0 & 100 & 100 & 100 & 100 & 1 & $<0.001$ \\
\hline $\begin{array}{l}\text { Burkhorderia } \\
\text { cepacia }\end{array}$ & 3 & 2 & 1 & 66.7 & 100 & 100 & 99.8 & 0.8 & $<0.001$ \\
\hline Enterobacter fecalis & 6 & 5 & 1 & 83.3 & 100 & 100 & 99.8 & 0.91 & $<0.001$ \\
\hline $\begin{array}{l}\text { Total Gram } \\
\text { negative }\end{array}$ & 204 & 186 & 8 & 96.1 & 100 & 100 & 97.7 & 0.97 & $<0.001$ \\
\hline Fungus & 11 & $\mathbf{0}$ & 11 & $\mathbf{0}$ & 0 & 0 & 0 & 0 & $1 \mathrm{NS}$ \\
\hline
\end{tabular}


Table.4 Identification results of polymicrobial cultures

\begin{tabular}{|l|l|}
\hline $\begin{array}{l}\text { Mixed culture identified by Vitek-MS routine } \\
\text { method }\end{array}$ & In-house protocol \\
\hline Pseudomonasstuzeri+staph epidermidis & No organism identified \\
\hline Klebsiella pneumoniae +Staph haemolyticus & Klebsiella pneumoniae \\
\hline Escherichia coli + staph epidermidis & Escherichia coli \\
\hline Pseudomonas aeruginosa + Klebsiella pneumoniae & No organism identified \\
\hline Escherichia coli + candida tropicalis & Escherichia coli \\
\hline Klebsiella pneumoniae + enterococcus fecalis & Klebsiella pneumoniae \\
\hline Burkhorderia cepacia + staph haemolyticus & No organism identified \\
\hline
\end{tabular}

Sepsis-related mortality can be greatly reduced by early initiation of adequate antimicrobial treatment. Identification of causative organisms can directly help the choice of appropriate antibiotic even before obtaining results of susceptibility testing. This decrease use of broad spectrum antibiotics which permit less reducing risk of potential development of antibiotic resistance (Vlek et al., 2012). It also reduces unnecessary antimicrobial therapy by identifying contaminated blood cultures (Osthoff et al., 2017).

Currently, blood pathogens are identified after subculturing on microbial culture media, thus makes turnaround time for microbial identification of positive blood culture about 24-48 hours. During this period the patient is treated empirically or untreated at all (Fenselau and Demirev, 2001).

MALDI-TOF has been established as rapid and accurate method for identification of cultured bacterial isolates. The use of this technology has been extended to allow direct bacterial identification from sterile body fluids (Singhal et al., 2015).

Using MALDI-TOF for identification pathogens directly from positive blood cultures is challenging issue. The presence of interfering substances such as such as charcoal (maybe present in blood culture bottles) and proteins from red cells, white blood cells, and serum may be problematic. These substances interfere with the analysis by generating additional spectral peaks not found in the organism database. Furthermore, low organism numbers (as might be encountered with slow-growing or contaminating bacteria) may be another challenge (Szabados et al., 2011)

Several commercial kits and in-house methods have been developed for preparation and extraction of microorganism from blood as purely as possible. However, the commercial kits, which were developed are still costly and require multiple complicated steps (Zhou et al., 2017).

In the current study we evaluated the performance of In house method for direct pathogen identification from blood, comparing obtained results with the conventional routine culture method. That is an important step to develop MALDI-TOF based workflow to shorten the time required for microbial identification of positive blood cultures. The results of our protocol showed good agreement with identification of the microorganisms subcultured on solid media. Overall, the performance of our protocol was excellent for Enterobacteriaceae, staph aureus, and Acinetobacter baumanii.

Total correct identification rate using our in- 
house protocol was $89.8 \%$. The correct identification rate of Gram positive bacteria were $88.8 \%$ while $96.1 \%$ of Gram negative bacteria were correctly identified. A previous study (Samaranayake et al., 2020)that used the same direct In-house protocol for MALDI-TOF MS identification reported higher correct identification rate for Gramnegative bacteria (99\%) but less correct identification rate for Gram-positive organisms $(84 \%)$.

The present study findings showed better identification of Gram negative than Gram positive bacteria. This was Consistent with other direct MALDI-TOF MS protocols, Martiny et al., 2012, reported $73.7 \%$ of correct identifications overall, with $86.4 \%$ correctly identified Gram-negative bacteria and $73.7 \%$ Gram-positive genera and species. Drancourt, 2010 found $94.0 \%$ for Gramnegative versus $67.0 \%$ for Gram-positive bacteria, Barberino et al., 2017 reported 84\% of correct identifications at the species level, with $93.5 \%$ being Gram-negative and78.5\% Gram-positive bacteria. The variation in results may be due to using different extraction protocols, different software, or difference in the proportion of gram positive and negative organisms.

Sensitivity of identification of Gram negative was higher than Gram positive using in-house protocol $(96.1 \%$ and $88.8 \%)$ respectively. Our findings are Consistent with other direct MALDI-TOF MS protocols that provided better identification of Gram negative than Gram positive bacteria, Identification of Gram positive by MS is known to be more difficult than Gram negative, this may be due to their thick cell wall (Bazzia et al., 2017; La Scola and Raoult, 2009; Rodríguez-Sánchez, 2014).

The present study reported $100 \%$ specificity and $96.1 \%$ sensitivity for Gram negative microorganisms.

Samaranayake et al., 2020, reported same specificity but higher sensitivity (99\%). For Gram positive microorganisms, specificity and sensitivity were (100\% and $88.8 \%)$ respectively. Samaranayake et al., reported lower specificity and similar sensitivity $(97.5 \%, 88.3 \%)$.

Our method were incapable if identifying yeasts, this may be due to their thick cell wall, making yeast identification by MS difficult. Disruption of yeast cell wall may require the more complex processing (Freimann et al., 2019)

For polymicrobial cultures, MALDI-TOF correctly identified one organism in 4/7 (57\%) blood culture bottles. Samaranayake et $a l ., 2020$ correctly reported one of the species present in $58 \%$ blood cultures and identified all organisms from 13\%poly-microbial blood culture bottles,

In conclusions this study demonstrated the effectiveness of In-house method for identifying bacteria directly from positive blood culture bottles. We propose our inhouse method as an efficient and successful method to reduce time of identification of causative agent of bacteremia/sepsis, which may help in rapid delivery of appropriate antibiotics to the patients

\section{Limitations}

Our in-house method was incapable of identifying yeast. Another limitation, the small number of poly-microbial cultures limit our study results.

\section{Ethical approval}

The study was conducted on blood culture bottles that were sent to microbiology 
laboratory as part of routine management of patients, so ethical approval was not required.

\section{References}

Bazzia, A.M., A.A Rabaanb, Z.E. Edailya, S. Johna, M.M Fawaraha and Al-Tawfiqc, J.A.2017. Comparison among four proposed direct blood culture microbial identification methods using MALDITOF MS. J Infect Public Health. 10,30815.

Barberino, M.G., M.O Silva, A.C.P. Arraes, L.C. Correia and Ana Verena Mendes. 2017. Direct identification from positive blood broth culture by matrix-assisted laser desorption-ionization time-of-flight mass spectrometry (MALDI-TOF MS) Braz J infect Dis. 21(3):339-342.

Bearman, G.M. and Wenzel, R. P. 2005. Bacteremias: a leading cause of death. Arch Med Res.36, 646-659. doi:10.1016/j.arcmed.2005.

Chen, J. H., P.L. Ho, G.S. Kwan, K.K. She, G.K. Siu, Cheng, V. C., et al., 2013. Direct bacterial identification in positive blood cultures by use of two commercial matrix-assisted laser desorption ionization-time of flight mass spectrometry systems. J Clin Microbiol. 51, 1733-9.

Chien, J. Y., T.F. Lee, S.H. Du, S.H. Teng, C.H. Liao, Sheng, W. H., et al., 2016. Applicability of an in-house saponinbased extraction method in Bruker biotyper matrix-assisted laser desorption/ionization time-of-flight mass spectrometry system for identification of bacterial and fungal species in positively flagged blood cultures. Front Microbiol. 7, 1432.

Delport, J., A., A. Strikwerda,A. Armstrong, D. Schaus and John, M. 2016. Quality of care is improved by rapid short incubation MALDI-TOF identification from blood cultures as measured by reduced length of stay and patient outcomes as part of a multi-disciplinary approach to bacteremia in pediatric patients. PLoS One2016; 11:e0160618.

Doern,C.D., andButler-Wu, S. M., 2016. Emerging and future applications of matrix-assisted laser desorption ionization time-of-flight (MALDI-TOF) mass spectrometry in the clinical microbiology laboratory: A report of the association for molecular pathology. J Mol Diagn. Nov; 18(6):789-802.

doi: 10.1016/j.jmoldx.2016.07.007.

Drancourt, M., 2010. Detection of microorganisms in blood specimens using matrix assisted laser desorption ionization time of flight mass spectrometry a review. Clin Microbiol Infect. 16, 1620-5.13.

Faron, M.L., B. W. Buchan, Ledeboer, N. A. 2017. Matrix-assisted laser desorption ionization-time of flight mass spectrometry for use with positive blood cultures: methodology, performance, and optimization. J Clin Microbiol. 55, 332838.

Fenselau, C., and Demirev, P.A. 2001. Characterization of intact microorganisms by MALDI mass spectrometry. Mass Spectrom Rev. 20, 157-171.

Freimann, S., M. Shapira and Athamna, A.2019 .Serum separator tube method for matrixassisted laser desorption/ionization timeof-flight analysis. Access Microbiol. Apr 16; 1(2):e000011.

doi: 10.1099/acmi.0.000011. e Collection 2019.PMID: 32974509.

La Scola, B., and Raoult, D.2009. Direct Identification of Bacteria in Positive Blood Culture Bottles by matrix-assisted laser desorption ionization time-of-flight mass spectrometry. PLoS ONE. 4 (11):e8041.

https://doi.org/10.1371/journal.pone.0008 041.

Martiny,D.,A. Dediste and Vandenberg,O.2012. Comparison of an in-house method and 
the commercial Sepsityper kit for bacterial identification directly from positive blood culture broths by matrixassisted laser desorption-ionization timeof-flight mass spectrometry. Eur J Clin Microbiol Infect Dis. 31, 2269-81.

Osthoff ,M.,N. Gürtler, S. Bassetti , G. Balestra, S. Marsch, H. Pargger, M. Weisser, Egli A.2017. Impact of MALDI-TOF-MSbased identification directly from positive blood cultures on patient management: a controlled clinical trial. Clin Microbiol Infect. 23, 78-85.

https://doi.org/10.1016/j.cmi.2016.08.009.

Rodríguez-Sánchez, B., C. Sánchez-Carrillo, A. Ruiz, M. Marín ,E. Cercenado, Rodríguez-Créixems M., et al.2014.Direct identification of pathogens from positive blood cultures using matrixassisted laser desorption-ionization timeof-flight mass spectrometry. Clin. Microbiol. Infect. 20 O421-O427. 10.1111/1469-0691.12455 - DOI PubMed.

Samaranayake, W.A.M.P, S. Dempsey, A.R. Howard-Jones, A.C. Outhred, and Kesson A.M.2020.Rapid direct identification of positive pediatric blood cultures by MALDI-TOF MS technology and its clinical impact in the pediatric hospital setting. BMC Res Notes. 13:12.https://doi.org/10.1186/s13104019-4861-4.

Singhal, N., M.Kumar, P.K. Kanaujia and Virdi, J.S.2015. MALDI-TOF mass spectrometry: an emerging technology for microbial identification and diagnosis. Front Microbiol. 6:791.

Szabados, F., M. Michels, M. Kaase, and Gatermann, S. 2011.The sensitivity of direct identification from positive BacT/ALERT (bioMérieux) blood culture bottles by matrix-assisted laser desorption ionization time-of-flight mass spectrometry is low. Clin. Microbiol. Infect. 17, 192-195.

Vlek, A.L., M.J., Bonten and Boel, C.H.2012. Direct matrix-assisted laser desorption ionization time-of-flight mass spectrometry improves appropriateness of antibiotic treatment of bacteremia. PLoS One; 7:e32589. doi: 10.1371/journal.pone.0032589 PMID: 22438880.

Zhou, M., Q. Yang, T. Kudinha, L. Sun, R. Zhang, Liu, C., et al., 2017.An improved in-house MALDI-TOF MS protocol for direct cost-effective identification of pathogens from blood cultures. Front Microbiol.8,1824.https://doi.org/10.3389/ fmicb.2017.01824

\section{How to cite this article:}

Amira Hamed Mohamed Afifi and Rehab Mohamed Mohamed Ateya. 2021. Evaluation of Simple In-house Method for Direct Microbial Identification of Positive Blood Culture by MALDI-TOF Technology. Int.J.Curr.Microbiol.App.Sci. 10(02): 1015-1023. doi: https://doi.org/10.20546/ijcmas.2021.1002.119 